\title{
O FENÔMENO RELIGIOSO: IDÉIAS SOBRE CONCEITO TIPOLÓGICO DE RELIGIÃO
}

\author{
Maria Emília Corrêa Da Costa*
}

\begin{abstract}
Resumo: Este artigo discute as relações entre a religião e as políticas sociais. Inicialmente aborda-se um conjunto de questões ligadas à liberdade religiosa como direito fundamental e a laicidade como separação entre o Estado e as confissões religiosas. Depois se apresentam os principais elementos do fenômeno religioso no campo jurídico, e a partir daí um conceito tipológico de religião que reúne características consideradas qualitativamente típicas desse fenômeno. Este conceito tipológico do termo religião ou de sua extensão no âmbito jurídico tem a função de, ao possibilitar a reflexão, evitar o desvirtuamento ou a distorção do seu sentido, que muitas vezes leva à discriminação e à interferência estatal indevida em matéria religiosa.
\end{abstract}

Palavras chave: Liberdade religiosa - laicidade - políticas sociais - Estado

\begin{abstract}
This article discusses the relationship between religion and social politics. Initially it addresses a range of issues related to religious freedom as a fundamental right and secularism as the separation between the State and religious denominations. Then it presents the main elements of the religious phenomenon in the legal field, and from there a typological concept of religion that combines characteristics considered qualitatively typical of this phenomenon. This typological concept of the term religion or of its extension under legal terms has the function, in allowing debate, to avoid the misrepresentation or distortion of its meaning, which often leads to discrimination and undue state interference in religious matters.
\end{abstract}

Keywords: Freedom of religion - secularism - social politics - State

\section{LIBERDADE RELIGIOSA E LAICIDADE}

O debate sempre atual sobre a questão da religião e das políticas sociais envolve questões paralelas que dizem com a liberdade religiosa e a laicidade. Nesse sentido, antes que adentremos diretamente na questão objeto deste trabalho, cumpre fazer um breve resgate das noções de liberdade religiosa como direito fundamental e da laicidade como separação entre o Estado e as confissões religiosas. 
A liberdade religiosa configura, em um sentido amplo, a liberdade do espírito em matéria religiosa, ou de opção do indivíduo em matéria de religião. Daí poder ser traduzida como uma forma de manifestação da liberdade de consciência, compreendendo o direito de liberdade de crença, de culto e de organização religiosa.

Deve restar protegida a esfera individual de cada cidadão de qualquer interferência ou pressão externa, seja por parte do Estado ou de terceiros, no que tange às opções de crença. E, tratando-se de uma liberdade, a proteção há de se estender a quaisquer decisões que o indivíduo tome em matéria religiosa, seja a opção pela crença, pela descrença, pela mudança de crença, pelo agnosticismo, etc. Da mesma forma impõe-se a garantia da manifestação externa da crença professada, que se dá através de atos de culto, embora nesse caso possam ocorrer restrições quando houver concorrência com outros direitos fundamentais.

Nesse sentido, na obra dirigida por Gregório Peces-Barba Martinez e Eusébio Fernández García, são apontadas as seguintes características básicas da liberdade religiosa em um Estado constitucional: a) a garantia em favor dos imperativos da consciência individual frente a qualquer intromissão, tanto dos poderes públicos, como de particulares; b) o respeito a um princípio de igualdade ou de não-discriminação por motivos religiosos, ideológicos ou de consciência, isto é, o indivíduo não pode ser objeto de tratamento desigual em função de quaisquer que sejam seus princípios morais e, conseqüentemente, de qualquer que seja a sua conduta de acordo com tais princípios; e c) a neutralidade dos poderes públicos, que supõe, tanto o compromisso de não exercer nenhuma perseguição ou coação por motivos de consciência, quanto a obrigação de não estabelecer discriminações injustificadas em favor (ou contra) os cidadãos em função de suas crenças. ${ }^{1}$

Dessa configuração da liberdade religiosa decorre a neutralidade do Estado em matéria religiosa e a sua separação das 
confissões religiosas - laicidade. Isso não afasta, contudo, a necessidade de compatibilizar o exercício de tal direito com os demais valores e princípios da ordem jurídica e com os direitos dos demais indivíduos, de modo a promover o bem comum.

Nesse sentido, a laicidade impõe ao poder público - por seus representantes - que se abstenha de tomar quaisquer medidas ou fundamentar quaisquer decisões com base em entendimentos religiosos. Os valores ou interesses religiosos não podem ser usados como parâmetros nem tampouco como elementos norteadores dos atos estatais. Daí a afirmação de Daniel Sarmento no sentido de que:

A laicidade do Estado, consagrada no art. 19, inciso I, da Constituição, não significa apenas a inexistência de uma religião oficial no país. Mais que isso, ela impõe a completa separação entre religião e Estado, tanto para proteger as confissões religiosas de indevidas intervenções dos governantes de plantão, como para assegurar aos cidadãos que as decisões dos poderes do Estado sejam sempre tomadas com fundamento em razões públicas, e não a partir de dogmas de qualquer credo religioso, ainda que majoritário. Estado laico não significa Estado ateu, pois o ateísmo não deixa de ser uma concepção religiosa. Na verdade, o Estado laico é aquele que mantém uma postura de neutralidade e independência em relação a todas as concepções religiosas, em respeito ao pluralismo existente em sua sociedade.

Num país como o Brasil, em que convivem lado a lado pessoas das mais diversas religiões, além de ateus e agnósticos, a laicidade do Estado representa garantia fundamental da igualdade e da liberdade dos cidadãos. Numa sociedade democrática, o poder não-público, tal como, por exemplo, a autoridade das igrejas sobre seus membros, é livremente aceito. ${ }^{2}$

De certo modo, a laicidade traduz-se, na busca do mais amplo exercício do direito fundamental de liberdade religiosa, na não utilização do elemento religioso para a legitimação do poder público. Nesse aspecto, o elemento religioso na sociedade deverá desenvolver-se livre de

$1 \quad$ História de los derechos fundamentales, Madrid: Editorial Dykinson, 2003. Tomo I, p.268

Daniel Sarmento, Lula subverteu o estado laico. Jornal O Globo. Rio de Janeiro, 18/09/2005, Primeiro Caderno, Editorial: Opinião. Disponível em: <http//www.arquivoglobo.com >, acesso em: 24/09/2005. O artigo trata da manifestação do presidente brasileiro, Luiz Inácio Lula da Silva, no sentido de que, tendo em vista seu 
qualquer ingerência estatal, bem como o Estado poderá atuar em decorrência da vontade cidadã que pressupõe o pluralismo de idéias e crenças.

\section{O FENÔMENO RELIGIOSO}

Essa breve análise da liberdade religiosa e da laicidade converge para um ponto comum: o elemento religioso - a religião. Daí a necessidade de se aclarar ou delinear, no âmbito jurídico, a noção de religião, para o fim de fornecer ferramentas que ajudem a atuação dos operadores do direito e demais operadores sociais no trato com as questões que dizem com a liberdade religiosa, a laicidade do Estado e demais temas correlatos, tais como a relação destes dois conceitos - liberdade religiosa e laicidade - com a formulação e execução de políticas públicas.

Assim, qual seria o conceito ou a extensão da religião que é tutelada pelo direito fundamental de liberdade religiosa, que elemento é esse que deve ser diferenciado da idéia de Estado, enfim, que elementos traduzem o religioso do ponto de vista jurídico?

A noção de religião, no âmbito jurídico constitucional, mostra-se, por vezes, muito vaga, fato que pode prestar-se a uma ampla interpretação, justificando discriminações ou interferências indevidas por parte do Estado em matéria religiosa.

Está claro que a religião, por sua própria natureza, não é um conceito uno, fechado. Não se está aqui a defender a conceituação absoluta e fechada do termo religião em um sentido legal, dispondo exaustivamente sobre os seus mais variados aspectos como faz, por exemplo, a legislação portuguesa através da Lei da Liberdade Religiosa - Lei no 16 de 21 de junho de 2001. Mas é certo que a questão está a pedir um delineamento de suas principais características.

respeito a "princípios cristãos", não apresentaria ao Congresso Nacional anteprojeto de lei sobre o aborto. 
Com efeito, a religião pode tomar vários sentidos, conforme o contexto histórico, filosófico, sociológico ou circunstancial em que é analisada, com maior ou menor amplitude. ${ }^{3}$ Nesse sentido, Beatriz González Moreno refere que:

a liberdade religiosa está conceitualmente vinculada à noção de religião e esta tem uma dimensão metajurídica - o plano sobrenatural -, e uma dimensão humana e social suscetível de numerosos enfoques. Ademais, se manifesta em uma pluralidade de religiões muito diferentes entre si, ainda que qualificadas por certos traços comuns. ${ }^{4}$

Ainda que se apresente de forma variada, conforme as épocas e os lugares, os tipos de Estado e os regimes políticos, e em conseqüência da própria diversidade das religiões ${ }^{5}$ o fenômeno religioso pressupõe, na lição de Marilena Chauí, "que, além do sentimento da diferença entre natural e sobrenatural, haja o sentimento da separação entre os humanos e o sagrado, mesmo que este habite os humanos e a natureza" 6

Nesse aspecto, a origem da palavra religião, apontada com freqüência, é a do latim: religio, formada pelo prefixo re (outra vez, de novo) e o verbo ligare (ligar unir, vincular); expressa, portanto, a idéia de vínculo entre o mundo profano e o mundo sagrado. ${ }^{7}$

Em um sentido amplo, John Finnis, ao elencar as formas básicas de bem humano, entende a religião como uma preocupação do ser humano com uma ordem de coisas "mais além" de todos e de cada um dos

\footnotetext{
3

De observar que o termo religião é comumente tomado na língua pátria, segundo o Dicionário Houaiss da Língua Portuguesa, como: 1 culto prestado a uma divindade; crença na existência de um ente supremo como causa, fim ou lei universal 2 conjunto de dogmas ou práticas de uma confissão religiosa 3 manifestação desse tipo de crença por meio de doutrinas e rituais próprios 4 crença, devoção, piedade 5 reverência às coisas sagradas (...) 8 qualquer filiação a um sistema específico de pensamento ou crença que envolve uma posição filosófica, ética, metafísica etc. Dicionário Houaiss da língua portuguesa. $1^{\text {a }}$ ed. Rio de Janeiro: Objetiva, p. 2422.

4 Estado de cultura, derechos culturales y libertad religiosa, Madrid: Civitas 2003, p. 249.

Jorge Miranda, Manual de direito constitucional, Tomo IV, Coimbra: Coimbra, 1993, p. 355

${ }_{6}$ Convite à filosofia. São Paulo: Ática, 2001, p. 298.
} 
homens, que o leva a questionar as origens da ordem cósmica e da liberdade e razão humanas, qualquer que seja a resposta a essa pergunta, ainda que agnóstica ou negativa. ${ }^{8}$

No âmbito da fenomenologia da religião, pode-se tomar a lição da Juan Martin Velasco, quando propõe a construção de uma categoria que possa abarcar todas as configurações do que entende ser o "mais além" do humano, ou sagrado, que seria o 'mistério', assim:

onde quer que se produza a presença de realidades, objetos, comportamentos, instituições marcadas pelos traços do "sagrado", imerso em sua "atmosfera", encontraremos a referência a um mais além da vida ordinária do homem, do mundo de que ele dispõe. Este mais além pode ser representado e tem sido representado de fato sob formas mais diversas, como Deus, os deuses, o sobrenatural, o divino, o Absoluto, a Potência, o invisível. Em alguma forma extrema pode ser representado sob a forma de ausência de toda a representação como no budismo primitivo que por isso aparece paradoxalmente como religião "atéia". Porém, nem sequer nesses casos falta a referência do homem a esse mais além de si mesmo, ainda que sua presença só se deixe sentir sob essa forma de ausência que testemunha a realidade chave do nirvana. Essa realidade foi designada entre as tradições teístas com a judio-cristã-islâmica como Deus. [...] Porém, está claro que a variedade de suas configurações não permite essa redução a uma de suas formas sem certa violência às tradições religiosas não expressamente teístas. ${ }^{9}$

Essa é, aliás, a característica tomada por Émile Durkheim, na sociologia da religião, para definir o pensamento religioso:

A divisão do mundo em dois domínios que compreendem, um, tudo que é sagrado, o outro, tudo que é profano, tal é o traço distintivo do pensamento religioso: as crenças, os mitos, os gnomos, as lendas, são representações ou sistemas de representações que exprimem a natureza das coisas sagradas, as virtudes e os poderes que lhes são atribuídos, sua história, suas relações mútuas e com as coisas profanas. Mas por coisas sagradas, convém não entender simplesmente esses seres pessoais que chamamos deuses ou espíritos:[...]O círculo dos objetos

Marilena Chauí, Convite à filosofia, p. 298.

John Finnis, Ley natural y derechos naturales, Buenos Aires: Abeledo-Perrot, 2000, p. 120-121.

Juan Martín Velasco. Fenomenologia de la religión. In:Manuel Fraijó. Filosofia de la religión: estúdios y textos. Madrid: Trotta, 1994, p. 76-77. Para o autor, o 'mistério' designaria o conjunto de traços nos quais coincidem as diferentes referências dos homens de todos os tempos quando se introduzem no mundo do sagrado. 
sagrados não pode, portanto, ser determinado de uma vez por todas; sua extensão é infinitamente variável conforme as religiões. Eis de que maneira o budismo é uma religião: é que, na falta de deuses, ele admite a existência de coisas sagradas, que são as quatro verdades santas e as práticas que delas derivam. ${ }^{10}$

$[\ldots]$

Quando um certo número de coisas sagradas mantém entre si relações de coordenação e de subordinação, de maneira a formar um sistema dotado de uma certa unidade, mas que não participa ele próprio de nenhum outro sistema do mesmo gênero, o conjunto das crenças e dos ritos correspondentes constitui uma religião. ${ }^{11}$

Para Émile Durkheim, além desse sistema de cultos dotados de certa autonomia, faz-se necessária, para caracterizar a religião, a sua adoção por uma coletividade determinada, em que os indivíduos se sintam ligados uns aos outros pelo fato de terem uma fé em comum. Desse modo, "uma sociedade cujos membros estão unidos por representarem da mesma maneira o mundo sagrado e por traduzirem essa representação comum em práticas idênticas, é isso a que chamamos uma igreja". ${ }^{12}$

Max Weber, por sua vez, ao fazer um estudo do desenvolvimento progressivo das idéias sobre aquilo que é religioso ou mágico nas mais diversas sociedades, utiliza a distinção entre o sagrado e o profano e apresenta sua distinção entre a igreja e a seita, ao analisar a relação entre a religião e o mundo. Assim, para o autor, a seita ostenta uma religiosidade caracterizada pela pureza de sua doutrina, pelo rigor moral e

\footnotetext{
10 As formas elementares da vida religiosa. São Paulo: Martins Fontes, 2003, p. 1820.

11 As formas elementares da vida religiosa..., p. 24. Nesse sentido, Peter Berger, em sua obra de sociologia da religião, na qual defende que o pluralismo religioso evidencia o enfraquecimento da religião na atualidade, parte da afirmação de que "a religião é o empreendimento humano pelo qual se estabelece o cosmos sagrado.[...] Por sagrado entende-se aqui uma qualidade de poder misterioso e temeroso, distinto do homem e todavia relacionado com ele, que se acredita residir em certos objetos da experiência. [...] O sagrado é apreendido como algo que 'salta para fora' das rotinas normais do dia a dia, como algo de extraordinário e potencialmente perigoso, embora seus perigos possam ser domesticados e sua força aproveitada para as necessidades cotidianas. [...] O homem enfrenta o sagrado como uma realidade imensamente poderosa distinta dele. Essa realidade a ele se dirige, no entanto, e coloca a sua vida numa ordem, dotada de significado". Peter Berger, O dossel sagrado: elementos para uma teoria sociológica da religião. São Paulo: Paulus, 1985, p. 38-39.

12 As formas elementares da vida religiosa, p. 28. Convém destacar que, ao associar a religião à existência da igreja, Durkheim a distingue da magia. Daí que esta última,
} 
um distanciamento em relação ao mundo. Já a igreja caracteriza-se por estar orientada para o mundo, no sentido de influenciá-lo e adaptar-se a ele. ${ }^{13}$

Da mesma forma, esse delineamento do fenômeno religioso está presente na análise de Mircea Eliade sobre o sagrado e o profano no mundo moderno, quando se refere especificamente às posições assumidas pelo homem em relação ao universo espiritual, afirmando que:

o homem religioso assume um modo de existência específica no mundo, e, apesar do grande número de formas histórico-religiosas, este modo específico é sempre reconhecível. Seja qual for o contexto histórico em que se encontra, o homo religiosus acredita sempre que existe uma realidade absoluta, o sagrado, que transcende este mundo, que aqui se manifesta, santificando-o e tornando-o real. Crê, além disso, que a vida tem uma origem sagrada e que a existência humana atualiza todas as suas potencialidades na medida em que é religiosa, ou seja, participa da realidade.

$[\ldots]$

É fácil ver tudo o que separa este modo de ser no mundo da existência de um homem a-religioso. Há antes de tudo o fato de que o homem a-religioso nega a transcendência, aceita a relatividade da "realidade", e chega até a duvidar do sentido da existência. $^{14}$

A reunião das conceituações acima expostas vem auxiliar o intérprete do fenômeno religioso, visto que a questão atinente à definição de religião (a ser empregada no discurso jurídico-constitucional sobre a liberdade religiosa) toma relevo na discussão sobre a amplitude da proteção da liberdade em estudo, no sentido de se saber se abrangeria tão somente as chamadas grandes religiões do mundo contemporâneo (como o judaísmo, o islamismo, os vários ramos do cristianismo, o hinduismo, o budismo, entre outras), ou se também incluiria seitas, quase-religiões, novos movimentos religiosos e outras minorias religiosas.

prescindindo da idéia de igreja, como necessidade de unir-se em confraria, não se inclui no conceito de religião. Idem, ibidem, p. 29.

13 Max Weber, Economia y sociedad, México: Fondo de Cultura Econômica, 1998, p. $_{14} 45$ e 932 .

O sagrado e o profano: a essência das religiões. São Paulo: Martins Fontes, 2001, p. 164-165. Para Mircea Eliade, a história das religiões demonstra a presença constante de manifestações de realidades sagradas, estando-se sempre "diante do mesmo ato misterioso: a manifestação de algo 'de ordem diferente' - de uma realidade que não pertence ao nosso 
O pressuposto aqui é o de que não se pode conceber a liberdade religiosa a partir de um conceito restritivo de religião. Fazendo assim, corre-se o risco de serem excluídos grupos religiosos minoritários, mais recentes ou menos conhecidos, em função da adoção de parâmetros exclusivamente advindos de movimentos tradicionais ou convencionais.

Tampouco parece possível adotar um conceito substancial fechado de religião, sem se incorrer em exclusões ou discriminações que não condizem com o perfil da liberdade religiosa hodierna. Nem mesmo é aceitável um conceito subjetivo de religião, pelo qual se contaria com a sinceridade com que a crença é sustentada pelo indivíduo, uma vez que isto implicaria uma atuação inquisitorial do órgão julgador da crença alheia; ou levaria à perda de objetividade por falta de critério no trato das questões atinentes à liberdade religiosa. ${ }^{15}$

Assim, na busca de uma conceituação de religião que não seja nem tão restrita (a ponto de tornar-se excludente), nem tão ampla (a ponto de abranger manifestações ideológicas e filosóficas sem cunho religioso), ainda que eventualmente protegidas por outros direitos fundamentais, poder-se-á adotar os critérios da similitude e do contraste com as várias religiões conhecidas, utilizando-se um conceito tipológico, ou que parte de elementos considerados típicos do fenômeno religioso. ${ }^{16}$

Na precisa lição de Jónatas Machado, deverão ser critérios de caráter meramente indicativo, não decisivo, aqueles externos ao fenômeno religioso, tais como:

a idade da crença, o seu valor social aparente, o número de seus aderentes, o seu grau de institucionalização, a sua forma de organização coletiva, a existência de clero ou de uma classe sacerdotal, as exigências éticas e morais que encerra, a consciência

mundo - em objetos que fazem parte integrante do nosso mundo "natural', "profano". $O$ sagrado e o profano...p. 17.

15 Jónatas Machado. Liberdade Religiosa, p. 214-216.

16 De referir que o Tribunal Europeu de Direitos Humanos, no caso Campbell e Cosans contra o Reino Unido (25/02/85), considerou que a liberdade religiosa "se aplica às convicções religiosas que obtiveram um certo grau de força, seriedade, de coerência e de importância”. Teresa Freixes Sanjuán. La construción jurisprudencial europea de la libertad religiosa. In: Antonio Marzal. Libertad religiosa y derechos humanos. Barcelona: J. M. Bosch Editor, 2004, p. 64. 
da conduta de seus aderentes, a existência de escritos sagrados, de dogmas e funções cerimoniais, etc. ${ }^{17}$

Pertinente acrescentar, neste passo, o posicionamento de Luis Fernando Barzotto, segundo o qual "ninguém sabe a priori qual é o conteúdo do bem da pessoa humana e do bem comum, indicados nos direitos e nos valores expressos na constituição", 18 pelo que "o conhecimento dos direitos individuais e sociais e dos valores está sempre sendo construído, de modo democrático, pelo diálogo que caracteriza o uso público da razão prática", ${ }^{19}$ mas, ainda assim, é necessário partir-se de um conceito ao menos parcialmente determinado de um télos final. Deste modo, a seguir-se essa linha de entendimento, embora se utilize um conceito tipológico aberto de religião para os fins da preservação da liberdade religiosa, tal conceituação deverá estar conectada com um télos ou objetivo fornecido previamente pela Constituição.

Com efeito, ainda que o conteúdo de um direito ou valor expresso na Constituição não possa emergir de imediato da simples disposição legal, certo é que a sua própria inclusão no texto constitucional decorre de sua gradual sedimentação na cultura de um povo, de seu reconhecimento pela comunidade, facilmente detectável na sua trajetória histórica.

Disso se impõe a necessidade de inserção do conceito de religião no sistema constitucional vigente. Nesse particular, deve-se ter presente que a liberdade religiosa, sobretudo na ordem jurídica pátria,

17

Idem, ibidem, p. 219-220. É de valia, ainda, para tal conceituação a concepção de razoável apresentada por John Rawls, quando analisa, dentre outras questões, a sociedade democrática ocidental, que parte de um pluralismo de "doutrinas abrangentes e razoáveis", incluindo as doutrinas religiosas. Seguindo o entendimento do autor, seriam consideradas abrangentes e razoáveis as doutrinas - no caso as religiosas -, que, num exercício de razão teórica, dissessem respeito aos aspectos religiosos da vida humana de uma maneira mais ou menos consistente e coerente, organizando e caracterizando valores reconhecidos de modo que fossem compatíveis entre si e expressassem uma visão de mundo inteligível; ainda, dessem primazia a certos valores, de forma a tornarem-se distintas de outras, envolvendo também um exercício de razão prática; e finalmente se baseassem em uma tradição de pensamento ou doutrina, ainda que passíveis de evolução ou alteração. John Rawls. $O$ liberalismo político. São Paulo: Ática, 2000, p.103.

18 A democracia na constituição, p. 206. 
secular e democrática, está incluída em um contexto constitucional que busca assegurar o exercício dos direitos individuais, da liberdade, da segurança, da igualdade e da justiça em uma sociedade fraterna, pluralista e sem preconceitos, ${ }^{20}$ devendo ser exercida dentro desses parâmetros. Assim entendido, a própria definição de religião em uma análise jurídica deve estar em acordo com a concepção apresentada pelo ordenamento jurídico brasileiro. $^{21}$

Com efeito, a adoção de critérios para a interpretação do fenômeno religioso se faz cada vez mais necessária. Isso porque é crescente o número de grupos que, apesar de apresentarem um perfil religioso, muitas vezes conduzem “à destruição da pessoa no plano psíquico (algumas vezes físico, muitas vezes financeiro), de sua família, das pessoas que a cercam e da sociedade, com o objetivo de levá-la a aderir sem restrições e a participar de uma obra que fere os direitos do homem e do cidadão", 22 não podendo estar incluídos na proteção da liberdade religiosa.

No resumo de María José Ciáurriz:

no campo jurídico e político a religião não pode ser definida; o Estado tem que se guiar de algum modo para respeitar a um só tempo a liberdade religiosa dos cidadãos - que sói ser por natureza expansiva, proselitista - e o bem social, não colocando instrumentos estatais ou sociais de nenhum tipo a serviço de interesses não religiosos disfarçados de religiosidade. ${ }^{23}$

19 Idem, ibidem, p. 207.

20 Segundo o Preâmbulo e arts. $1^{\circ}$ a $5^{\circ}$ da Constituição da República Federativa do Brasil. BRASIL. Constituição. Brasília: Senado Federal, 2000.

21 De referir que, para Luis Fernando Barzotto, a constituição pátria é teleológica, pelo fato de que "determina certos bens como finalidades da sociedade e do Estado". Assim, partindo do liberalismo de Dworkin, pelo qual o governo deve ser neutro sobre a questão da vida boa (good life), afirma que a constituição brasileira, ao contrário, não é liberal, "não é neutra acerca do que é a vida boa para o ser humano. Ela contém uma determinada concepção de vida boa". Luis Fernando Barzotto, A democracia na constituição, Porto Alegre: Unisinos, 2003, p. 193. E, ainda que não se adote o entendimento de que a Constituição tenha uma determinada concepção de vida boa, certo é que a ordem jurídica elenca determinados valores como sendo fundamentais para a organização social e para a garantia da dignidade da pessoa humana. Assim, o pensamento liberal, ainda que proponha a neutralidade do Estado no que concerne ao conceito de vida boa, também busca garantir aqueles direitos fundamentais necessários ao desenvolvimento da pessoa humana em todas as suas dimensões.

22 Bernard Fillaire, As Seitas, São Paulo: Ática, 1997, p. 6. 
Certamente não se está a questionar, aqui, práticas religiosas próprias de cada religião, seita ou movimento religioso que possam implicar restrições no comportamento individual, pois, como explica Michael Walzer, "praticamente todas as religiões toleradas querem restringir a liberdade individual [...] as religiões, de um modo geral, são organizadas para controlar o comportamento". ${ }^{24}$ E haverá, dentro de uma ordem pluralista, confissões religiosas mais ou menos afetas à idéia de liberdade religiosa, mais ou menos tolerantes.

Também há que se evitar a tendência, presente na sociedade moderna, de adotar uma postura anti-culto, ou seja, que toma por suspeita qualquer ritual ou experiência religiosa mais intensa, sob pena de se ferir a garantia da liberdade religiosa.

\section{ELEMENTOS CONSIDERADOS TÍPICOS NO FENÔMENO RELIGIOSO - UMA PROPOSTA}

Destarte, a partir dos entendimentos e conceitos ora recolhidos, cumpre propor um conceito tipológico de religião (que reúne características consideradas qualitativamente típicas desse fenômeno), pelo que a religião, para o fim da análise do direito de liberdade religiosa no âmbito deste trabalho, deve apresentar as seguintes características:

1) o reconhecimento da diferenciação entre sagrado e profano, entendido o sagrado como o que está além - e diverso - da ordem de coisas ligadas à natureza e à rotina do homem nesse mundo (o profano);

2) a formação de uma relação de coordenação e subordinação entre essas coisas tomadas como sagradas, de modo a formar um sistema de crença com certa unidade e coerência;

3) a adoção de tal conjunto de crenças por um grupo de pessoas;

23 El derecho de proselitismo en el marco de la libertad religiosa. Madrid: Centro de estúdios políticos y constitucionales, 2001, p. 40.

24 Da tolerância, São Paulo: Martins Fontes, 1999, p. 92. 
4) o reconhecimento desse grupo de pessoas, em função da crença adotada, pela comunidade na qual está inserido;

5) o respeito, no exercício dessa crença (ações - rituais e práticas religiosas), aos valores básicos pátrios explicitados pela Constituição, de modo a conformar-se com a ordem pública constitucional.

É de se ter presente, ainda, que as diversas denominações que podem ser encontradas para os grupos relacionados ao fenômeno religioso tais como igrejas, seitas, minorias religiosas ou movimentos religiosos -, por si só não estabelecem o seu perfil religioso ou não-religioso para os fins da tutela da liberdade religiosa e demais temas correlatos. Sempre será necessária, como referido, a análise das manifestações e doutrinas de cada movimento para concluir que se está ou não frente a um fenômeno religioso tutelável pela liberdade religiosa. Tudo isso levando-se em conta as características apresentadas nos cinco itens acima.

Nesse aspecto, como alerta Jónatas Machado, o próprio termo "igreja", utilizado nos textos constitucionais, deve apresentar-se destituído "de um relevo jurídico particular, limitando-se a refletir cognitivamente o contexto histórico-cultural envolvente, densamente impregnado pela linguagem e pelos símbolos cristãos". ${ }^{25}$ Logo, o vocábulo deve ser interpretado em termos amplos, a fim de incluir o fenômeno religioso em toda a sua extensão, com diversidade de comunidades e grupos que têm uma unidade e um mesmo fim religioso.

\section{CONCLUSÃO}

Os elementos aqui apresentados com o escopo de fomentar uma conceituação do fenômeno religioso, mormente quando utilizado no âmbito jurídico-constitucional, não têm a pretensão de encerrar uma verdade absoluta ou um conceito fechado. Antes, têm a finalidade de trazer à

$25 \quad$ A liberdade religiosa... p. 237. 
discussão a necessidade premente de formar uma noção mais concreta do que seja religião, sobretudo para os casos em que nos defrontamos com institutos jurídicos que utilizam este termo para os mais variados fins, seja para limitar ou garantir direitos, para regulamentar práticas sociais, ou em outros tantos fatos que influem das maneiras mais diversas na vida de todos e de cada um de nós.

$\mathrm{O}$ aclaramento do termo religião ou de sua extensão no âmbito jurídico, como antes referido, tem a função de, ao possibilitar a reflexão, evitar o desvirtuamento ou a distorção do seu sentido, que muitas vezes leva à discriminação e à interferência estatal indevida em matéria religiosa.

Quando se fala na garantia da liberdade religiosa, na preservação da laicidade, na necessidade de criar e manter políticas públicas sem a interferência de dogmas eminentemente religiosos, no respeito ao pluralismo religioso, e em outras tantas matérias que dizem com o fenômeno religioso, há que se ter em mente uma idéia mínima do que seja religião para esses fins. Caso contrário, estar-se-á fundando o debate sobre bases frágeis, uma vez que não se pode prescindir de uma noção do que seja o elemento que une toda a discussão sobre o fenômeno religioso na atualidade - a religião!

\section{REFERÊNCIAS}

BARZOTTO, Luis Fernando. A democracia na constituição. Porto Alegre: Unisinos, 2003.

BERGER, Peter. O dossel sagrado: elementos para uma teoria sociológica da religião. São Paulo: Paulus, 1985.

BRASIL. Constituição. Brasília: Senado Federal, 2000.

CHAUI, Marilena de Souza. Convite à filosofia.12.ed. São Paulo: Ática, 2001.

CIÁURRIZ, Maria José. El derecho de proselitismo en el marco de la libertad religiosa. Madrid: Centro de estúdios políticos y constitucionales, 2001.

DICIONÁRIO HOUAISS DA LÍNGUA PORTUGUESA. $1^{\mathrm{a}}$ ed. Rio de Janeiro: Objetiva. 
DÍEZ-PICAZO, Luis María. Sistema de Derechos Fundamentales. Madrid: Civitas, 2003.

DURKHEIM, Émile. As formas elementares da vida religiosa. São Paulo: Martins Fontes, 2003.

ELIADE, Mircea. O sagrado e o profano: a essência das religiões. São Paulo: Martins Fontes, 2001.

FILLAIRE, Bernard. As seitas. São Paulo: Ática, 1997.

FINNIS, John. Ley natural y derechos naturales, Buenos Aires: Abeledo-Perrot, 2000.

FRAIJÓ, Manuel (org). Filosofia de la religión: estúdios y textos. Madrid: Trotta, 1994.

GONZÁLEZ MORENO, Beatriz. Estado de cultura, derechos culturales y libertad religiosa. Madrid: Civitas, 2003.

MACHADO, Jónatas Eduardo Mendes. A liberdade religiosa numa comunidade constitucional inclusiva. Coimbra: Coimbra Editora, 1996.

MARZAL, Antonio (org). Libertad religiosa y derechos humanos. Barcelona: J. M. Bosch Editor, 2004.

MIRANDA, Jorge. Manual de direito constitucional. 2.ed. Coimbra: Coimbra Editora, 1998. Tomo IV.

PECES-BARBA MARTINEZ, Gregório; FERNANDEZ GARCIA, Eusébio (dir). Historia de Los Derechos Fundamentales. Madrid: Dykinson, 1998. Tomo I.

RAWLS, John. O liberalismo político. São Paulo: Ática, 2000.

SARMENTO, Daniel. Lula subverteu o estado laico. Jornal O Globo. Rio de Janeiro, 18/09/2005, Primeiro Caderno, Editoria: Opinião. Disponível em: <http//www.arquivoglobo.com >, acesso em: 24/09/2005.

WALZER, Michael. Da tolerância. São Paulo: Martins Fontes, 1999.

WEBER, Max. Economia y sociedad. México: Fondo de Cultura Econômica, 1998. 